\title{
PAPER
}

\section{Differential effects of three interferon betas on neutralising antibodies in patients with multiple sclerosis: a follow up study in an independent laboratory}

\author{
A Bertolotto, S Malucchi, A Sala, G Orefice, P B Carrieri, M Capobianco, E Milano, \\ F Melis, M T Giordana
}

\begin{abstract}
Objective: To evaluate the incidence and the prevalence of neutralising antibodies (NABs) to three interferon beta (IFN $\beta$ ) products in patients with multiple sclerosis (MS).

Methods: Sera were tested from 125 patients with relapsing-remitting MS. Patients were treated with IFN $\beta$-1 lb (Betaferon, $n=29$ ) 8 MIU subcutaneously every other day, IFN $\beta$-1 a (Avonex, $\mathrm{n}=44$ ) $30 \mu \mathrm{g}$ intramuscularly once weekly, or IFN $\beta$-1 a (Rebif, $n=36$ ) $22 \mu \mathrm{g}$ subcutaneously three times weekly for 6 to 18 months. An additional 16 patients were treated with Rebif $22 \mu \mathrm{g}$ intramuscularly once or twice weekly. NABs were assessed using the cytopathic effect assay before treatment and every three months during treatment. Patients with two or more consecutive positive samples were considered to be persistent $\mathrm{NAB}$ positive $(\mathrm{NAB}+)$.

Results: At baseline, no patients were $N A B+N A B$ s developed during the first three months of treatment and continued to develop until month 18. Over 18 months of treatment, the risk of being persistent $\mathrm{NAB}+$ was 31\% for Betaferon, 15\% for Rebif, and 2\% for Avonex (Betaferon versus Avonex, $\mathrm{p}=0.001$; Betaferon versus Rebif, $\mathrm{p}=0.19$; Rebif versus Avonex, $\mathrm{p}=0.04)$. In all patients with one or more $\mathrm{NAB}+$ samples, the risk of becoming $\mathrm{NAB}+$ was $38 \%$ for Betaferon, $18 \%$ for Rebif, and $7 \%$ for Avonex (Betaferon versus Avonex, $p=0.0007$; Betaferon versus Rebif, $p=0.10$; Rebif versus Avonex, $p=0.07$ ). At month 18, the prevalence of persistent $N A B+$ patients was $31.6 \%$ for Betaferon, $18.7 \%$ for Rebif, and $4 \%$ for Avonex. Numbers of NAB+ patients observed were similar with intramuscular Rebif and with subcutaneous Rebif.

Conclusion: The three IFN $\beta$ preparations have different degrees of immunogenicity, with Betaferon producing the highest incidence of NABs and Avonex the lowest. These differences should be considered by neurologists when selecting treatment for their patients with MS because NABs can reduce both bioavailability and clinical efficacy of IFN $\beta$.
\end{abstract}

Correspondence to: Dr A Bertolotto, Centro Sclerosi Multipla \& Laboratorio di

Neurobiologia Clinica, Divisione Universitaria di Neurologia, Azienda Ospedaliera S Luigi di Orbassano, Università di Torino-Regione Piemonte Regione Gonzole 10, 10043, Orbassano, Italy; nsglb@tin.it

Received for publication 26 November 2001 In revised form 16 April 2002

Accepted 18 April 2002
$P$ atients with multiple sclerosis (MS) can develop neutralising antibodies (NABs) during treatment with interferon beta (IFN $\beta$ ) products: IFN $\beta$-Ib (Betaferon; Schering AG, Berlin, Germany), ${ }^{12}$ IFN $\beta$-la (Avonex; Biogen, Inc, Cambridge, UK), ${ }^{3}{ }^{4}$ and IFN $\beta$-la (Rebif; Ares-Serono, Basel, Switzerland). ${ }^{5}$ The presence and concentration of NABs may be clinically important in the management of patients treated with IFN $\beta$ s because $\mathrm{NAB}$-positive $(\mathrm{NAB}+)$ patients have low or undetectable serum concentrations of IFN $\beta .{ }^{6}$ Furthermore, NABs reduce or abolish IFN $\beta$ bioavailability ${ }^{7-10}$ and NABs have been shown to reduce the therapeutic efficacy of IFN $\beta$ s. ${ }^{12} 5^{2} 9^{11-16}$

The reported percentages of $\mathrm{NAB}+$ patients observed in studies of individual IFN $\beta$ s vary considerably. ${ }^{1-3} 59$ 17-21 However, a direct comparison of the percentages of $\mathrm{NAB}+$ patients reported in these studies is not possible because of differences in assay methods in different laboratories, including differences in the following parameters: type of assay used to detect NABs; methods used to represent neutralisation potency; criteria for determining $\mathrm{NAB}$ positivity; three month versus six month time points for measurement; and treatment duration.

The present study was conducted to determine the incidence and prevalence of NABs in serum samples from patients with MS who were treated with Betaferon, Avonex, or Rebif for 6 to 18 months. NABs were quantified every 3 months using the cytopathic effect (CPE) assay in a single laboratory in our MS centre. Hence, NABs were directly compared for the three IFN $\beta$ products under controlled conditions in a single laboratory using the same assay procedure.

\section{METHODS}

\section{Patients}

Patients with clinically definite $\mathrm{MS}^{22}$ were enrolled in the study from May 1995 to July 2000. Patients were included in the study if they were between 17 and 65 years of age, had a relapsing-remitting or secondary progressive course of $\mathrm{MS}^{23}$ and had an expanded disability status scale (EDSS) ${ }^{24}$ score of $\leqslant 5.5$. Patients were excluded from the study if they had received prior treatment with an IFN $\beta$ product, immunosuppressive treatment during the 12 months before the study, or corticosteroids four weeks before the initiation of the study. Patients who were pregnant or breastfeeding, had other neurological or autoimmune diseases, or had infectious conditions were excluded from the study. Before enrolment, all aspects of the study protocol were reviewed with each patient and informed consent was obtained.

\section{Procedure}

Eligible patients were screened for the presence of NABs before (baseline) and every 3 months during IFN $\beta$ treatment for up to 18 months. Patients were treated with one of the

Abbreviations: CPE, cytopathic effect; EDSS, expanded disability status scale; IFN $\beta$, interferon beta; LU, laboratory units; MS, multiple sclerosis; $N A B$, neutralising antibody; PRISMS, prevention of relapses and disability by interferon $\beta$-la subcutaneously in multiple sclerosis; $\mathrm{WHO}$ World Health Organization 
three commercially available IFN $\beta$ preparations: Betaferon 8 MIU subcutaneously three times weekly, Avonex $30 \mu \mathrm{g}$ intramuscularly once weekly, or Rebif $22 \mu \mathrm{g}$ subcutaneously three times weekly. An additional subgroup of patients was treated with Rebif $22 \mu \mathrm{g}$ intramuscularly once or twice weekly. Patients were not randomly assigned to treatment because the three IFN $\beta$ s became available in Italy at different times: Betaferon in February 1995, Avonex in August 1997, and Rebif $22 \mu \mathrm{g}$ in December 1998. Moreover, all the patients treated with Avonex had an EDSS score $\leqslant 3.5$ because the Avonex phase III study included patients in this score range. ${ }^{3}$ Blood samples were collected every 3 months at least 36 hours after IFN $\beta$ injection, then serum was inactivated for 30 minutes at $56^{\circ} \mathrm{C}$ before being stored at $-80^{\circ} \mathrm{C}$ until assayed.

Two categories of $\mathrm{NAB}$ positive $(\mathrm{NAB}+)$ patients were identified. The first category consisted of all patients who had one or more positive sample. The second category, a subset of the first category, consisted of patients who had two or more consecutive $\mathrm{NAB}+$ samples, referred to as "persistent" NAB + .

\section{Cytopathic effect assay}

The CPE assay was used to detect NABs because it has been recommended by the World Health Organization (WHO). ${ }^{25}$ A549 cells (human lung carcinoma cell line) were plated in a monolayer on to 96 well tissue culture plates at a mean concentration of 70000 cells/100 $\mu$ l and incubated overnight. Serum samples were diluted, mixed with one of the three IFN $\beta$ preparations at a final concentration of $10 \mathrm{IU} / \mathrm{ml}$, and incubated for one hour. One hundred microlitres of the serum-IFN $\beta$ mixture was incubated with A549 cells for 24 hours. Cells were then infected with encephalomyocarditis murine virus and viable cells were quantified 24 hours later by staining with crystal violet in $20 \%$ ethanol. The dye taken up by the cells was eluted with $33 \%$ acetic acid and its absorbance was measured in a densitometer at $620 \mathrm{~nm} .{ }^{18}$ Controls for viral activity, cellular viability, and titration of the IFN $\beta$ preparation were performed in each set of CPE assays for NAB detection.

According to WHO recommendations, data from the neutralisation assay are reported as the reciprocal of the highest dilution of serum inducing 50\% neutralisation (that is, neutralising $10 \mathrm{U} / \mathrm{ml}$ of IFN activity to an apparent $1 \mathrm{U} / \mathrm{ml}$ of activity). The neutralisation titre of a serum sample was calculated according to Kawade's formula ${ }^{26}$ and expressed in laboratory units (LU). A concentration of $\geqslant 20 \mathrm{LU} / \mathrm{ml}$ is generally considered the threshold for positivity. However, the present study used thresholds of both $\geqslant 5$ and $\geqslant 20 \mathrm{LU} / \mathrm{ml}$ because the lower limit of detection for our CPE assay was $2.5 \mathrm{LU} / \mathrm{ml}$. The IFN $\beta$ s used as reference or calibration standards in the CPE assay were the commercially available preparations of Betaferon, Avonex, and Rebif intended for clinical use.

\section{Statistical analysis}

The percentage of patients who developed NABs during each three month period was calculated to determine the incidence of $\mathrm{NAB}+$ patients in each treatment group. The risk of becoming $\mathrm{NAB}+$ was assessed from the incidence of $\mathrm{NAB}+$ patients over sequential three month intervals using Kaplan-Meier analysis, in which patients are included in the analysis until they become NAB + or drop out of the study. Differences in survival curves between the treatment groups were analysed using the log rank test. Prevalence was computed from the number of patients presenting as NAB + in cumulative three month periods during the study. Prevalence was calculated from baseline to 3, 6, 12, 15, and 18 months of treatment. Differences in the prevalence of $\mathrm{NAB}+$ samples between the treatment groups were analysed using Fisher's exact test. All statistical analyses were performed with GraphPad Prism software, version 3.0 (GraphPad Software Inc, San Diego, California, USA). All reported p values are based on two tailed statistical tests, with a significance level of 0.05 .
Table 1 Patient demographic and clinical characteristics

\begin{tabular}{|c|c|c|c|}
\hline & $\begin{array}{l}\text { Betaferon } \\
(\mathrm{n}=29)\end{array}$ & $\begin{array}{l}\text { Avonex } \\
(\mathrm{n}=44)\end{array}$ & $\begin{array}{l}\text { Rebif } \\
(n=52)\end{array}$ \\
\hline \multicolumn{4}{|l|}{ Sex } \\
\hline Male & 9 & 14 & 13 \\
\hline Female & 20 & 30 & 39 \\
\hline \multicolumn{4}{|l|}{ Age (years) } \\
\hline Mean (SD) & $35.5(10.8)$ & $35.2(9.9)$ & $39.3(10.4)$ \\
\hline Range & $21-62$ & $19-60$ & $17-64$ \\
\hline \multicolumn{4}{|l|}{ EDSS score } \\
\hline Mean (SD) & $2.4(1.3)$ & $1.2(0.8)$ & $2.2(1.1)$ \\
\hline Range & $0-5.5$ & $0-3.5$ & $1-4.5$ \\
\hline \multicolumn{4}{|c|}{ Disease duration (years) } \\
\hline Mean (SD) & $7.8(6.2)$ & $8.0(7.8)$ & $7.8(7.2)$ \\
\hline Range & $0.5-22$ & $0.5-40$ & $0.08-24$ \\
\hline \multicolumn{4}{|c|}{ Treatment duration (months) } \\
\hline Mean (SD) & $15.4(4.2)$ & $14.8(4.3)$ & $15.0(4.4)$ \\
\hline Range & $6-18$ & $6-18$ & $6-18$ \\
\hline
\end{tabular}

EDSS, expanded disability status scale.

\section{RESULTS}

\section{Patients}

One hundred twenty five patients were enrolled in the study. Twenty nine patients received Betaferon, 44 patients received Avonex, and 36 patients received Rebif. A subgroup of 16 patients received Rebif intramuscularly once (6 patients) or twice ( 10 patients) weekly. Follow up was comparable among the treatment groups. All patients $(n=125)$ completed six months of treatment and were included in the analyses of baseline, month 3, and month 6. Sixty patients $(48 \%)$ completed 18 months of treatment: 19 of 29 patients (65\%) in the Betaferon group, 25 of 44 patients (57\%) in the Avonex group, and 16 of 36 patients (44\%) in the Rebif subcutaneously group. The mean treatment duration for all groups was 15 months, and 675 serum samples were available for analysis (77 samples were not available). Sixty five of 125 patients (52\%) did not have a complete follow up; 50 patients were still receiving treatment when the study ended; 15 of 125 (12\%) discontinued the treatment because of disease progression (five patients), side effects (five patients), pregnancy (one patient), and personal choice (four patients). All the dropout patients were NAB negative.

Table 1 shows the baseline demographic and clinical characteristics of patients. There were no significant differences between groups in demographic or clinical characteristics at baseline with the exception of a lower EDSS score of patients treated with Avonex. The majority of patients (71\%) were women and the mean age of all patients was 36.6 years. No patients tested positive for NABs at baseline.

\section{NAB titre $\geqslant 20 \mathrm{LU} / \mathrm{ml}$}

Table 2 presents the incidences of all $\mathrm{NAB}+$ patients and persistent $\mathrm{NAB}+$ patients with an antibody titre $\geqslant 20 \mathrm{LU} / \mathrm{ml}$ for each treatment group. NABs were first detected during the first 3 months of treatment and continued to appear throughout the 18 months of treatment. Of 21 patients who developed NABs during the 18 month study, 19 (90\%) developed NABs during the first year of treatment, $16(84 \%)$ of these during the first nine months of treatment. The risk of becoming persistent NAB + during 18 months of IFN $\beta$ treatment was $31 \%$ with Betaferon, 15\% with Rebif, and 2\% with Avonex (fig 1A). The risk of becoming persistent $\mathrm{NAB}+$ was significantly lower for Avonex than for either Betaferon $(p=0.001)$ or Rebif $(p=0.04)$. There was no difference in the risk of developing NABs between Betaferon and Rebif $(p=0.19)$. In an analysis that included patients with one isolated $\mathrm{NAB}+$ sample (fig $1 \mathrm{~B})$, the risk of becoming $\mathrm{NAB}+$ increased for all groups and was 38\% with Betaferon, $18 \%$ with Rebif, and 7\% with Avonex 
Table 2 Incidence (Inc) and prevalence (Prev) of neutralising antibodies (NABs) (titre $\geqslant 1: 20$ ) in patients with multiple sclerosis treated with interferon beta

\begin{tabular}{|c|c|c|c|c|c|c|c|c|c|c|c|c|c|c|c|}
\hline \multirow[b]{3}{*}{ Months } & \multicolumn{5}{|c|}{ Betaferon } & \multicolumn{5}{|c|}{ Avonex } & \multicolumn{5}{|c|}{ Rebif } \\
\hline & \multirow[b]{2}{*}{$\mathrm{n}$} & \multicolumn{2}{|c|}{ All NAB + (\%) } & \multicolumn{2}{|c|}{ Persistent NAB+ (\%) } & \multirow[b]{2}{*}{$\mathrm{n}$} & \multicolumn{2}{|c|}{ All NAB+ (\%) } & \multicolumn{2}{|c|}{ Persistent NAB+ (\%) } & \multirow[b]{2}{*}{$\mathrm{n}$} & \multicolumn{2}{|c|}{ All NAB + (\%) } & \multicolumn{2}{|c|}{ Persistent NAB+ $(\%)$} \\
\hline & & Inc & Prev & Inc & Prev & & Inc & Prev & Inc & Prev & & Inc & Prev & Inc & Prev \\
\hline 0 & 29 & 0 & 0 & 0 & 0 & 44 & 0 & 0 & 0 & 0 & 36 & 0 & 0 & 0 & 0 \\
\hline $0-3$ & 29 & 0 & 0 & 0 & 0 & 44 & 0 & 0 & 0 & 0 & 36 & 2.8 & 2.8 & 0 & 0 \\
\hline $3-6$ & 29 & 20.7 & 20.7 & 0 & 0 & 44 & 2.3 & 2.3 & 0 & 0 & 36 & 5.7 & 8.3 & 2.8 & 2.8 \\
\hline $6-9$ & 26 & 20.0 & 34.6 & 19.2 & 19.2 & 39 & 2.6 & 2.6 & 0 & 0 & 29 & 3.8 & 10.3 & 7.1 & 6.9 \\
\hline $9-12$ & 24 & 7.1 & 41.7 & 5.3 & 25.0 & 36 & 0 & 2.8 & 2.8 & 2.8 & 26 & 9.1 & 19.2 & 4.3 & 11.5 \\
\hline $12-15$ & 22 & 0 & 45.4 & 6.2 & 31.8 & 30 & 3.6 & 6.7 & 0 & 3.3 & 22 & 0 & 18.2 & 5.5 & 18.2 \\
\hline $15-18$ & 19 & 0 & 42.1 & 8.3 & 31.6 & 25 & 0 & 8.0 & 0 & 4.0 & 16 & 10.0 & 25 & 0 & 18.7 \\
\hline
\end{tabular}

All $N A B+$, patients who had $\geqslant 1$ positive serum samples; Persistent $N A B+$, patients who had $\geqslant 2$ consecutive positive serum samples.
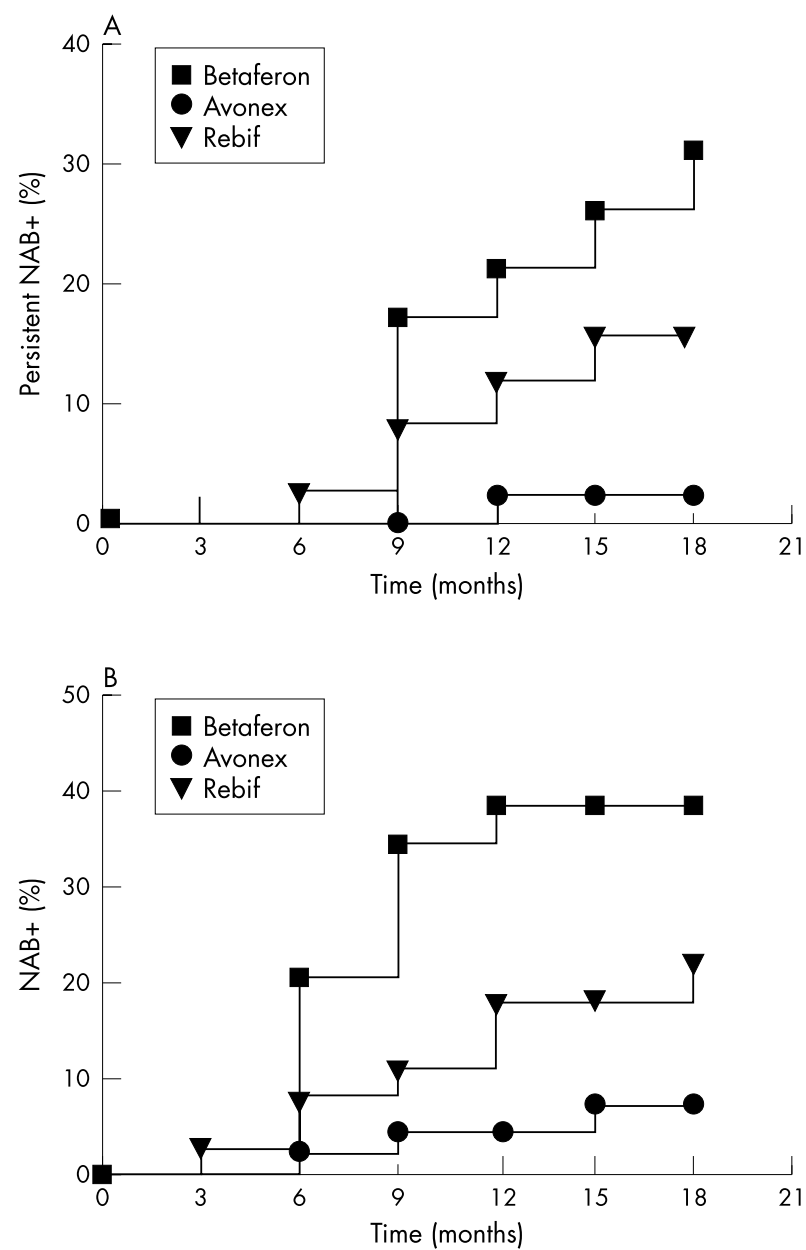

Figure 1 Kaplan-Meier curves for risk of having $(A)$ two or more consecutive samples positive for neutralising antibodies (persistent $\mathrm{NAB}+)$ and $(\mathrm{B})$ one or more positive samples $(\mathrm{NAB}+)$ using a titre $\geqslant 20 \mathrm{LU} / \mathrm{ml}$ as the threshold for positivity.

(Betaferon versus Avonex, $\mathrm{p}=0.0007$; Betaferon versus Rebif, $\mathrm{p}=0.10$; Rebif versus Avonex $\mathrm{p}=0.07$ ).

The prevalence of NABs was significantly higher in Betaferon treated patients than in Avonex treated patients at all cumulative time points after month 3 for all $\mathrm{NAB}+$ patients and for persistent $\mathrm{NAB}+$ patients $(\mathrm{p}=0.0002$ to $\mathrm{p}=0.03$; table 2). At month 18, the cumulative prevalence of persistent $\mathrm{NAB}+$ patients was $31.6 \%$ in the Betaferon group compared with $4 \%$ in the Avonex group. Patients treated with Rebif had a cumulative prevalence of $25 \%$ and $18.7 \%$ after 18 months for all $\mathrm{NAB}+$ and persistent $\mathrm{NAB}+$, respectively. There was no significant difference between Rebif and either Betaferon or Avonex.

\section{NAB titre $\geqslant 5 \mathrm{LU} / \mathrm{ml}$}

Table 3 shows the incidence of $\mathrm{NAB}+$ patients with the threshold for positivity defined as a $\mathrm{NAB}$ titre $\geqslant 5 \mathrm{LU} / \mathrm{ml}$ (table 3, fig 2A). The data obtained were consistent with those of NAB titre $\geqslant 20 \mathrm{LU} / \mathrm{ml}$. A significantly lower risk of becoming persistent $\mathrm{NAB}+$ was observed in the Avonex group than in either the Betaferon group $(p=0.0002)$ or the Rebif group $(p=0.047)$; the difference between Betaferon and Rebif approached significance $(p=0.068)$. In an analysis of the risk for having one or more NAB + samples, a significantly lower risk of developing NABs was observed in the Avonex group than in either the Betaferon or the Rebif group $(p=0.0001$ and $\mathrm{p}=0.003$, respectively). Similar to the data for titre $\geqslant 20 \mathrm{LU} / \mathrm{ml}$, there was no significant difference in the risk of NAB development between Betaferon and Rebif treatments (fig 2B).

The prevalence of NABs was also evaluated for all NAB+ patients and the subgroup of persistent $\mathrm{NAB}+$ patients having an antibody titre $\geqslant 5 \mathrm{LU} / \mathrm{ml}$ (table 3 ). As expected from this lowered detection threshold, the prevalence of NAB + patients was higher across all treatment groups at each interval for both categories of patients (table 3). The prevalence of NAB+ patients and persistent $\mathrm{NAB}+$ patients was significantly greater in the Betaferon group than in the Avonex group $(p<0.0001$ to $p=0.03)$. In the Rebif group, the prevalence of NABs in all patients and persistent NAB + patients was 50\% and $18.7 \%$, respectively, but there was no significant difference between the Rebif group and either the Avonex or the Betaferon group.

\section{NABs in patients treated with intramuscular Rebif}

A subgroup of 16 patients were treated with Rebif $22 \mu \mathrm{g}$ intramuscularly once or twice weekly. The route of administration of Rebif did not affect the development of NABs. The incidence of persistent $\mathrm{NAB}+$ patients in this subgroup was $18.7 \%$, which was similar to the incidence observed in patients who received Rebif $22 \mu \mathrm{g}$ subcutaneously three times weekly (19.7\%). Two of the three NAB+ patients were treated with Rebif $22 \mu \mathrm{g}$ intramuscularly once weekly, whereas the third patient received Rebif $22 \mu \mathrm{g}$ intramuscularly twice weekly.

\section{DISCUSSION}

The present study directly compared the incidence and prevalence of NABs with the three types of IFN $\beta$ s available in Europe for the treatment of relapsing MS. Results showed that the three IFN $\beta$ preparations differ in their ability to induce NABs in patients with MS. A significantly lower incidence of $\mathrm{NAB}+$ patients was observed with Avonex than with either Betaferon or Rebif for both definitions of NAB positivity (one 
Table 3 Incidence (Inc) and prevalence (Prev) of NABs (titre $\geqslant 1: 5$ ) in patients with multiple sclerosis treated with interferon beta

\begin{tabular}{|c|c|c|c|c|c|c|c|c|c|c|c|c|c|c|c|}
\hline \multirow[b]{3}{*}{ Months } & \multicolumn{5}{|c|}{ Betaferon } & \multicolumn{5}{|c|}{ Avonex } & \multicolumn{5}{|c|}{ Rebif } \\
\hline & \multirow[b]{2}{*}{$n$} & \multicolumn{2}{|c|}{ All NAB + (\%) } & \multicolumn{2}{|c|}{ Persistent NAB+ (\%) } & \multirow[b]{2}{*}{$n$} & \multicolumn{2}{|c|}{ All NAB+ (\%) } & \multicolumn{2}{|c|}{ Persistent NAB+ (\%) } & \multirow[b]{2}{*}{1} & \multicolumn{2}{|c|}{ All NAB + (\%) } & \multicolumn{2}{|c|}{ Persistent NAB+ $1 \%$} \\
\hline & & Inc & Prev & Inc & Prev & & Inc & Prev & Inc & Prev & & Inc & Prev & Inc & Prev \\
\hline 0 & 29 & 0 & 0 & 0 & 0 & 44 & 0 & 0 & 0 & 0 & 36 & 0 & 0 & 0 & 0 \\
\hline $0-3$ & 29 & 0 & 0 & 0 & 0 & 44 & 0 & 0 & 0 & 0 & 36 & 2.8 & 2.8 & 0 & 0 \\
\hline $3-6$ & 29 & 24.1 & 24.1 & 0 & 0 & 44 & 6.8 & 6.8 & 0 & 0 & 36 & 17.1 & 16.7 & 2.8 & 2.8 \\
\hline $6-9$ & 26 & 26.3 & 38.4 & 19.2 & 19.2 & 39 & 2.8 & 5.1 & 2.6 & 2.6 & 29 & 13.6 & 20.7 & 7.1 & 6.9 \\
\hline $9-12$ & 24 & 16.7 & 50.0 & 21.0 & 37.5 & 36 & 3.1 & 5.5 & 0 & 2.8 & 26 & 12.5 & 30.8 & 8.7 & 15.4 \\
\hline $12-15$ & 22 & 12.5 & 59.0 & 7.7 & 40.9 & 30 & 4.0 & 6.7 & 0 & 3.3 & 22 & 20 & 40.9 & 0 & 18.2 \\
\hline $15-18$ & 19 & 25.0 & 63.1 & 0 & 36.8 & 25 & 0 & 8.0 & 0 & 4.0 & 16 & 50 & 50.0 & 0 & 18.7 \\
\hline
\end{tabular}
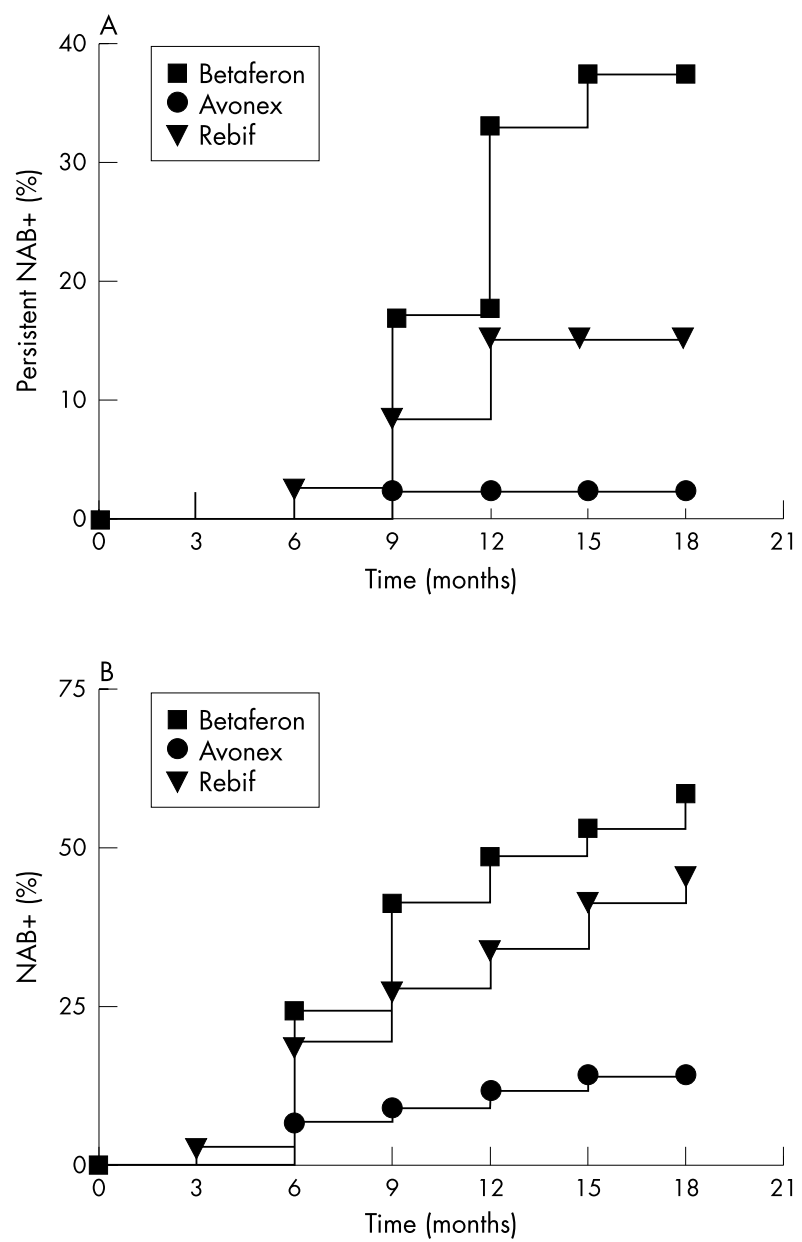

Figure 2 Kaplan-Meier curves for risk of becoming $(A)$ persistent $N A B+$ and $(B) N A B+$ using a titre $\geqslant 5 \mathrm{LU} / \mathrm{ml}$ as the threshold for positivity.

or more positive samples and two ore more positive samples). The cumulative risk of becoming persistent $\mathrm{NAB}+$ with Betaferon was double that of Rebif $(31 \% \vee 15 \%)$ and over 10 -fold greater than that for Avonex (31\% v 2\%). The cumulative risk of becoming persistent $\mathrm{NAB}+$ with Rebif was approximately 7 -fold greater than that for Avonex (15\% v 2\%). Hence, Betaferon was more immunogenic than Rebif and Rebif was more immunogenic than Avonex. As expected, lowering the threshold criteria for NAB positivity from a detection limit of $\geqslant 20 \mathrm{LU} / \mathrm{ml}$ to $\geqslant 5 \mathrm{LU} / \mathrm{ml}$ increased the incidence of NABs in each treatment group; however, patients treated with Avonex still had a significantly lower risk of developing NABs than did patients treated with Betaferon or Rebif.
The presence of NABs is important in the evaluation of IFN $\beta$ efficacy in the treatment of MS. All double blind, placebo controlled, randomised, multicentre trials that established the beneficial effects of IFN $\beta$ s for the treatment of relapsing MS reported the incidence of NABs. ${ }^{1-5}$ In these clinical studies of individual IFN $\beta$ s, the percentage of $\mathrm{NAB}+$ patients ranged from $27.8 \%$ to $45 \%$ with Betaferon, ${ }^{12}{ }^{27}$ from $15.9 \%$ to $23.8 \%$ with Rebif, ${ }^{518}$ and from $2 \%$ to $22 \%$ with Avonex. ${ }^{34}$ The findings of the present study are generally consistent with the results of these studies, with the exception that the percentage of $\mathrm{NAB}+$ patients observed in the phase III trial of Avonex was substantially higher (14-22\%). ${ }^{3}$ In the open label safety extension of the phase III Avonex trial, ${ }^{9}$ the percentage of $\mathrm{NAB}+$ patients decreased to $5 \%$; the decrease in NABs from the phase III study was attributed to a modifications of the manufacturing process to reduce the amount of IFN $\beta$-la aggregates by changing the excipients in the final product. ${ }^{9}$ The low incidences of $\mathrm{NAB}+$ patients found in our study and in a recent study of Avonex in monosymptomatic patients (2\% $\mathrm{NAB}+$ patients) ${ }^{4}$ are consistent with the idea that the available Avonex preparation is less immunogenic than that used in the phase III trial. ${ }^{9}$

The apparent rank order of immunogenicity of the three IFN $\beta$ preparations in the present study is consistent with a study by Ross et al, ${ }^{21}$ which compared the immunogenicity of all three IFN $\beta$ s in one laboratory using an antiviral neutralisation bioassay. This study found that Betaferon was more immunogenic than IFN $\beta$-la, and among IFN $\beta$-la products, Rebif was more immunogenic than Avonex. In another study by Kivisäkk et al, ${ }^{20}$ similar $\mathrm{NAB}+$ threshold criteria were applied to compare NAB development with Betaferon and Avonex using a CPE assay in an independent laboratory. In this study, the percentage of NABs was $44 \%$ with Betaferon and 5\% with Avonex in patients treated from 7 to 24 months. ${ }^{20}$

The CPE assay is internationally recognised for quantification of the neutralising activity of IFN $\beta s .{ }^{25}$ A titre $\geqslant 20 \mathrm{LU} / \mathrm{ml}$ is generally considered to be the threshold for NAB positivity and has been used in most studies. ${ }^{1258182028-30}$ Another approach to establishing a threshold for an upper limit of normal is to assess the lowest value detectable in IFN $\beta$ treated patients but not in healthy controls or in untreated patients with MS. The test used in the present study has a lower limit of sensitivity of $2.5 \mathrm{LU} / \mathrm{ml}$, and none of the patients had a concentration higher than $5 \mathrm{LU} / \mathrm{ml}$ before IFN $\beta$ treatment. Consequently, our data were stratified and analysed based on two thresholds, $\geqslant 5$ and $\geqslant 20 \mathrm{LU} / \mathrm{ml}$. Decreasing the threshold for positivity or using a method with a higher sensitivity increases the number of patients detected as positive. For example, Ross et al $^{21}$ used a sensitive method (to $3 \mathrm{LU} / \mathrm{ml}$ ) and found that most patients treated with IFN $\beta$ produced IFN $\beta$ antibodies, with $40 \%$ to $75 \%$ of patients NAB+. To date, it is not known whether the threshold for NAB positivity in the 
CPE assay should be $5 \mathrm{LU} / \mathrm{ml}$ or $20 \mathrm{LU} / \mathrm{ml}$ because the lowest $\mathrm{NAB}$ titre that interferes with the therapeutic efficacy of IFN $\beta$ has not been identified. However, it is noteworthy that a titre between 5 and $20 \mathrm{LU} / \mathrm{ml}$ decreases IFN $\beta$ bioavailability and a titre $>20 \mathrm{LU} / \mathrm{ml}$ abolishes bioavailability. ${ }^{8}$

Fluctuation of NAB positivity is possible and the disappearance of NABs after some years of treatment has been described..$^{16}$ Our study lasted 18 months, too short a follow up period to analyse NABs seroconversion. However, in the group of 14 persistent $\mathrm{NAB}+$ patients (with titre $>20 \mathrm{LU} / \mathrm{ml}$ ), all the samples were positive during the follow up, apart from two samples from the same patient in which positive determinations always showed a titre $<38 \mathrm{LU} / \mathrm{ml}$.

There are several potential reasons for the differences observed between the three IFN $\beta$ s in their ability to induce NABs. IFN $\beta$-lb differs from IFN $\beta$-la in several respects, such as biochemical structure, dose, dosing frequency, route of administration, and vehicle. ${ }^{61920}$ One or more of these factors may be responsible for the increased immunogenic properties of Betaferon compared with IFN $\beta$ - la (Rebif or Avonex). However, since IFN $\beta$-la is identical to natural IFN $\beta$, whereas IFN $\beta$ - $1 \mathrm{~b}$ has been modified biochemically, ${ }^{31}$ it is likely that biochemical structure is an important aspect in determining the high immunogenicity observed with Betaferon. The risk of developing NABs was also higher with Rebif than with Avonex; however, these two IFN $\beta$ products have the same biochemical structure. It can be hypothesised that differences in dose or route of administration affect immunogenicity. However, data from the present study do not support this hypothesis because the incidence of NABs did not differ between groups of patients treated with Rebif 22 or $44 \mu \mathrm{g}$ intramuscularly weekly and those treated with Rebif $66 \mu \mathrm{g}$ subcutaneously weekly. Hence, differences in immunogenicity between Avonex and Rebif may depend on differences in drug excipients. The relation between excipients and immunogenicity of IFN $\beta$ has not been studied, but Rudick et al ${ }^{9}$ suggest that a modification of the Avonex excipient caused a reduction in $\mathrm{NAB}+$ patients.

In contrast with the study of Antonelli et $a{ }^{18}{ }^{18}$ in our study the degree of disability did not seem to be a factor influencing the capacity to produce NABs, although the Avonex treated patients presented with a lower baseline EDSS score. In fact, $\mathrm{NAB}$ negative patients and persistent $\mathrm{NAB}+$ patients did not differ in baseline EDSS score, regardless of whether Avonex treated patients were included in the analysis. Moreover, NAB negative and persistent $\mathrm{NAB}+$ patients had comparable disease durations

As the majority of NABs appear during the first year of treatment, their clinical effects are more evident if the follow up is longer than two years. This concept is clearly shown by the PRISMS (prevention of relapses and disability by interferon $\beta$-la subcutaneously in multiple sclerosis) study, which showed no significant impact of NABs during the first two years of the study, but a significant impact on both clinical and magnetic resonance imaging measures when the follow up was four years. ${ }^{52}$ It should be noted that NABs have a relevant impact on MS in terms of both the number of patients involved and the magnitude of clinical effects. The PRISMS-4 study clearly showed that NAB + patients treated with Rebif $44 \mu \mathrm{g}$ three times weekly had a mean relapse rate of 0.81 and a $17 \%$ increase in burden of disease on magnetic resonance imaging, whereas NAB negative patients had 0.50 relapse rate and $8 \%$ decrease in burden of disease. This clinical effect was observed in one of seven patients treated with Rebif $44 \mathrm{\mu g}$ and in less than one of five patients $(23 \%)$ treated with Rebif $22 \mu g$.

In conclusion, this study compared the relative risk for developing NABs in patients with MS treated with one of three different IFN $\beta$ preparations using a single, sensitive assay under controlled conditions in one central laboratory. The rank of relative risk was found to be Betaferon $\geqslant$ Rebif $>$
Avonex. NABs can appear early during the course of MS treatment, persist for several years before disappearing ${ }^{16}$ decrease IFN $\beta$ bioavailability, ${ }^{89}$ and reduce or abolish the clinical efficacy of IFN $\beta$ s. ${ }^{12516}$ Hence, the relative risk of developing NABs should be considered when selecting the appropriate IFN $\beta$ treatment, both for newly diagnosed MS and for those already receiving treatment for MS.

\section{ACKNOWLEDGEMENTS}

We thank Prof G Antonelli for teaching us the CPE method; we are indebted to Rita Guerrieri and Angela Zaccaria for their expert nursing assistance. This work was supported by Piedmont Health Service, AISM (Associazione Italiana Sclerosi Multipla), ARB (Associazione Ricerca Biomedica), and Fondazione Cavalieri Ottolenghi.

Authors' affiliations

A Bertolotto, S Malucchi, A Sala, M Capobianco, E Milano, F Melis, M T Giordana, Centro di Riferimento Regionale Sclerosi Multipla \& Laboratorio di Neurobiologia Clinica, Divisione Universitaria di

Neurologia, Azienda Ospedaliera S Luigi, Università di Torino, Orbassano, Italy

G Orefice, P B Carrieri, Dipartimento Scienze Neurologiche; Università Federico II, Napoli, Italy

Competing interests: $A B, S M, G O, P B C, M C$, and $E M$ have been reimbursed by Farmades, Serono, and Dompè Biotech for attending several conferences; $A B$ received fees for speaking from Serono, Dompè Biotech, and Biogen; and $A B$ received funds for research and for members of the staff from Serono and Dompè Biotech. Farmades is the Italian distributor of Betaferon; Serono is the manufacturer of Rebif, Biogen is the manufacturer of Avonex, and Dompè Biotech is the Italian distributor of Avonex.

\section{REFERENCES}

1 IFNB Multiple Sclerosis Study Group, University of British Columbia MS/MRI Analysis Group. Neutralizing antibodies during treatment of multiple sclerosis with interferon beta-1b: experience during the first three years. Neurology 1996:47:889-94.

2 European Study Group on Interferon $\beta-1 \mathrm{~b}$ in Secondary Progressive MS. Placebo-controlled multicentre randomised trial of interferon $\beta-1 \mathrm{~b}$ in treatment of secondary progressive multiple sclerosis. Lancet 1998:352:1491-7.

3 Jacobs LD, Cookfair DL, Rudick RA, et al. Intramuscular interferon beta-l a for disease progression in relapsing multiple sclerosis. Ann Neurol 1996;39:285-94.

4 Jacobs LD, Beck RW, Simon JH, et al. Intramuscular interferon beta-1a therapy initiated during a first demyelinating event in multiple sclerosis. $N$ Engl J Med 2000;343:898-904.

5 Anon. PRISMS-4: long-term efficacy of interferon-beta- la in relapsing MS. Neurology 2001;56:1628-36.

6 Khan OA, Xia Q, Bever CT Jr, et al. Interferon beta- $1 \mathrm{~b}$ serum levels in multiple sclerosis patients following subcutaneous administration. Neurology 1996;46:1639-43.

7 Bertolotto A, Audano L, Bottero R, et al. IFNbeta bioavailability in multiple sclerosis patients: MxA mRNA quantification by competitive RT-PCR. J Neurol Sci 2000;21 (suppl 4):S158.

8 Deisenhammer F, Reindl $M$, Harvey $J$, et al. Bioavailability of interferon beta $1 \mathrm{~b}$ in MS patients with and without neutralizing antibodies. Neurology 1999;52:1239-43.

9 Rudick RA, Simonian NA, Alam JA, et al. Incidence and significance of neutralizing antibodies to interferon beta-la in multiple sclerosis. Neurology 1998;50:1266-72.

10 Trojano M, Avolio C, Liuzzi GM, et al. Changes in serum sICAM-1 and MMP-9 induced by rIFNbeta- $1 \mathrm{~b}$ treatment in relapsing-remitting MS. Neurology 1999;53:1402-8.

11 Arnason BG, Dianzani F. Correlation of the appearance of anti-interferon antibodies during treatment and diminution of efficacy: summary of an international workshop on anti-interferon antibodies. $J$ Interferon Cytokine Res 1998;18:639-44.

12 Bertolotto A, Bottero R, Magliola U, et al. Neutralizing antibodies reduce IFN beta efficacy in multiple sclerosis patients: a 3 year follow-up study in 66 multiple sclerosis patients. J Neurol Sci 2000:21/suppl 4):S167.

13 Bertolotto A, Malucchi S, Milano E, et al. Interferon $\beta$ neutralizing antibodies in multiple sclerosis: neutralizing activity and cross-reactivity with three different preparations. Immunopharmacology 2000;28:95-100

14 Pachner AR. Anticytokine antibodies in beta interferon-treated MS patients and the need for testing: plight of the practicing neurologist. Neurology 1997;49:647-50.

15 Paszner B, Petkau J, Oger J. Neutralizing antibodies to interferon- $\beta$ in the treatment of multiple sclerosis: cause for concern? CNS Drugs $1999 ; 11: 225-43$ 
16 Rice G, the PRISMS Study Group. Interferon-neutralizing antibodies reduce clinical and magnetic resonance imaging efficacy in multiple sclerosis patients treated with interferon $\beta$-la (Rebif): observations from the PRISMS 4-year extension study [abstract]. Ann Neurol 2000;48:477.

17 Abdul Ahad AK, Galazka AR, Revel M, et al. Incidence of antibodies to interferon beta in patients treated with recombinant human interferon beta-1 a from mammalian cells. Cytokine Cell Mol Ther 1997;3:27-32.

18 Antonelli G, Bagnato F, Pozzilli C, et al. Development of neutralizing antibodies in patients with relapsing-remitting multiple sclerosis treated with IFN-B la. J Interferon Cytokine Res 1998;18:345-50.

19 Antonelli G, Simeoni E, Bagnato F, et al. Further study on the specificity and incidence of neutralizing antibodies to interferon (IFN) in relapsing remitting multiple sclerosis patients treated with IFN beta-la or IFN beta-1b. J Neurol Sci 1999;168:131-6.

20 Kivisäkk P, Alm GV, Fredrikson S, et al. Neutralizing and binding anti-interferon- $\beta$ (IFN- $\beta$ ) antibodies: a comparison between IFN- $\beta$-la and IFN- $\beta-1$ b treatment in multiple sclerosis. Eur J Neurol 2000;7:27-34

21 Ross C, Clemmesen KM, Svenson M, et al. Immunogenicity of interferon- $\beta$ in multiple sclerosis patients: influence of preparation, dosage, dose frequency, and route of administration. Ann Neurol 2000;48:706-12.

22 Poser CM, Paty DW, Scheinberg L, et al. New diagnostic criteria for multiple sclerosis: guidelines for research protocols. Ann Neurol 1983;13:227-31.

23 Lublin FD, Reingold SC for the National Multiple Sclerosis Society (USA) Advisory Committee on Clinical Trials of New Agents in Multiple Sclerosis. Defining the clinical course of multiple sclerosis: results of an international survey. Neurology 1996;46:907-11.
24 Kurtzke JF. Rating neurologic impairment in multiple sclerosis: an expanded disability status scale (EDSS). Neurology 1983;33:1444-52. 25 WHO Expert Committee on Biological Standardization. Thirty-fifth report. WHO technical report series 725. Geneva: World Health Organization, 1985.

26 Kawade Y. Quantitation of neutralization of interferon by antibody. Methods Enzymol 1986;1 19:558-73.

27 IFNB Multiple Sclerosis Study Group. Interferon beta-1b is effective in relapsing-remitting multiple sclerosis. I. Clinical results of a multicenter, randomized, double-blind, placebo-controlled trial. Neurology 1993:43:655-61.

28 Knobler RL, Greenstein Jl, Johnson KP, et al. Systemic recombinant human interferon-beta treatment of relapsing-remitting multiple sclerosis: pilot study analysis and six-year follow-up. J Interferon Res

1993;13:333-40.

29 Myhr KM, Ross C, Nyland HI, et al. Neutralizing antibodies to interferon (IFN) alpha-2a and IFN beta-la or IFN beta-1 $\mathrm{b}$ in MS are not cross-reactive. Neurology 2000;55:1569-72.

30 The Once Weekly Interferon for MS Study Group (OWIMS) Evidence of interferon $\beta$-la dose response in relapsing-remitting MS. Neurology 1999;53:679-86.

31 Runkel L, Meier W, Pepinsky RB, et al. Structural and functional differences between glycosylated and non-glycosylated forms of human interferon- $\beta$ (IFN- $\beta$ ). Pharm Res 1998;15:641-9.

32 PRISMS (prevention of relapses and disability by interferon $\beta$-1a subcutaneously in multiple sclerosis) Study Group. Randomised double-blind placebo-controlled study of interferon $\beta$-la in relapsing/remitting multiple sclerosis. Lancet 1998;352:1498-504.

\section{HISTORICAL NOTE}

\section{van Swieten's concept of cerebral embolic stroke}

T he Swiss physician Johann Jakob Wepfer (1620-95) showed that apoplexy is due to cerebral haemorrhage. ${ }^{1}$ Vascular engorgement or congestion, not occlusion or stenosis, was at that time thought to cause nonhaemorrhagic (serous) apoplexy. Indeed even at the turn of the 19th century, Pinel and oth ers classed apoplexy as a form of cerebral neurosis. The distinction between thrombosis and haemorrhage was unclear until the mid 19th century, despite the clinical and pathological descriptions of Abercrombie Cheyne, ${ }^{4}$ Cooke, ${ }^{5}$ and in France, Serres. ${ }^{6}$ Small softenings were first designated lacunes by Dechambres in 1838 .

van Swieten postulated embolism arising in the heart and great vessels; far ahead of his time, he observed ${ }^{8}$ :

"It has been established by many observations that these polyps occasionally attach themselves as excrescences to the columnae carneae of the heart, and perhaps separate from it and are propelled, along with the blood, into the pulmonary artery or the aorta, and its branches ... were they thrown into the carotid or vertebral arteries, could disturb-or if they completely blocked all approach of arterial blood to the brain-utterly abolish all functions of the brain."
Gerhard van Swieten (1700-72) was a student of the famous Boerhaave in the lovely Dutch city of Leiden. Boerhaave had adopted the clinically orientated teachings of Willis and of Sydenham (the British Hippocrates) His work reflects the importance paid to orderly and critical clinical observations made at the bedside. He became the personal physician to the Empress Maria Theresa.

van Swieten published his Commentaria in Hermanni Boerhaave aphorismos de cognoscendis et curandis morbis, in six volumes (Lugduni Batavorum, J \& H Verbeek) between 1742-76. It was translated into English in 18 volumes in $1771-76^{8}$ In the commentaria he gave the first description, known to date, of episodic cluster headache. This text also includes his lucid accounts of podagra (gout), and of nominal aphasia in patients recovered from apoplexy.

Amongst his many other important works, van Swieten's idea that embolism could occlude the arteries of the brain and thereby be a major cause of loss of brain functionthat is, stroke-ranks as a signal advance, though not appreciated until more than a century later.

J M S Pearce

304 Beverley Road, Anlaby, HUL HU10 7BG, UK imspearce@freenet.co.uk

\section{References}

1 Wepfer JJ. Historiae apoplecticorum. 1658 In: (English translation) Bagvili. Practice of physik. London, 1704. Cited in: Major RH. Classic descriptions of disease. 3rd ed. Illinois: Charles C Thomas, 1945:474-7.

2 Lidell JA. A treatise on apoplexy, cerebral hemorrhage, cerebral embolism, cerebral rheumatism, and epidemic cerebro-spinal meningitis. Vol 8. New York: Wm Wood, 1873:xix, 395

3 Abercrombie J. Part 2: of the apoplectic affections. In: Pathological and practical researches on diseases of the brain and spinal cord. Edinburgh: Waugh and Innes, 1828.

4 Cheyne J. Cases of apoplexy and lethargy with observations on comatose patients. London: Underwood, 1812

5 Cooke J. A treatise on nervous disease. London: Longman, 1820-3.

6 LC McHenry. Garrison's history of Neurology. Revised. Springfield Illinois: Charles C Thomas, 1969:376-87.

7 Dechambre A. Mémoire sur la curabilité du ramollissement cérébral. Gazette Médicale (Paris) 1838;6:305-14

8 van Swieten G. Of the apoplexy, palsy and epilepsy. Commentaries on the aphorisms of Dr Herman Boerhaave. Translation from six volumes (Lugduni Batavorum, J \& H Verbeek, 1742-76). London: John \& Paul Knapton,

1754 , vol 10. 